\title{
UMA ANÁLISE REFLEXIVA DA ATUAÇÃO DO PROFISSIONAL ENFERMEIRO J UNTO À CONDIÇÃO DE ACIDENTADO DO TRABALHO, SEGUNDO A TEORIA DE PATERSON E ZDERAD
}

Krug SBF, Somavilla VC. Uma análise reflexiva da atuação do profissional enfermeiro junto à condição de acidentado do trabalho, segundo a teoria de Paterson e Zderad. Rev Latino-am Enfermagem 2004 março-abril; 12(2):277-9.

Esse artigo refere-se a uma análise crítica reflexiva da atuação do profissional enfermeiro junto à condição de acidentado do trabalho. Observa-se que, no âmbito das relações sociais, determinadas pelo sistema capitalista e revestidas pelo caráter utilitário, desponta o preconceito que passa a permear as relações com esses indivíduos. Os acidentados são identificados como pessoas incapazes para o trabalho e para a vida social, sendo prejudicados diretamente em suas relações, sofrendo brutalmente com essa situação. Como subsídio para atuação do profissional enfermeiro frente ao tema, foi utilizada a Teoria da Prática Humanista de enfermagem de Paterson e Zderad.

DESCRITORES: acidentes de trabalho; cuidados de enfermagem

\section{A REFLEXIVE ANALYSIS ON PROFESSIONAL NURSING ACTIONS INVOLVING WORK ACCIDENT VICTIMS IN VIEW OF THE THEORY OF PATERSON AND ZDERAD}

This article offers a reflexive critical analysis of professional nurses' actions regarding the injured worker's condition. It is observed that, in the context of social relations, which are determined by the capitalist system and characterized by utilitarianism, new biases emerge which permeate our relations with those individuals. The injured are identified as incapable of work and social life. Thus, they are directly impaired in their relationships and overtly suffer from this situation. As a basic tool to help the actions of nursing professionals in view of this issue, we used the Humanistic Theory by Paterson and Zderad.

DESCRIPTORS: occupational accidents; nursing care

\section{UNA ANÁLISIS REFLEXIVO DE LA ACTUACIÓN DEL PROFESIONAL} ENFERMERO CON RESPECTO A LAS CONDICIONES DE ACCIDENTADO DE TRABAJ O SEGUNDO LA TEORÍA DE PATERSON Y ZDERAD

Ese artículo busca hacer un análisis crítico cuyo objetivo es reflexionar sobre la actuación del profesional enfermero con respecto a las condiciones del que sufre un accidente de trabajo. Se encontró que en el ámbito de las relaciones sociales, determinadas por el sistema capitalista y envueltas por el carácter de utilidad, surge el perjuicio alrededor de las relaciones con estas personas. Los que sufren este tipo de accidente son identificados como personas sin capacidad para el trabajo y para la vida en sociedad, sufriendo terribles perjuicios en sus relaciones. Para ayudar al trabajo del profesional enfermero cuando esté frente al problema presentado, se ha utilizado la Teoría de la Práctica Humanista de Paterson y Zderad.

DESCRIPTORES: accidentes de trabajo; atención de enfermería

\footnotetext{
${ }^{1}$ Artigo elaborado na disciplina "Teorias de Enfermagem" ministrada pela Prof ${ }^{a}$ Drª Maria da Graça Crosseti no Programa de Mestrado em Enfermagem da Universidade Federal do Rio Grande do Sul - $1999 ;{ }^{2}$ Enfermeira, Mestre em Desenvolvimento Regional, Professor da Universidade de Santa Cruz do Sul, Pesquisador do Núcleo de Estudos e Pesquisa em Saúde-NEPS, e-mail: skrug@unisic.com.br
} 
INTRODUÇÃO

$\boldsymbol{A}$ Enfermagem é uma profissão caracterizada pela predominância, em suas atividades, do ato de cuidar. As alternativas para cuidar são muitas, e cabe ao enfermeiro, por meio de seus conhecimentos e habilidades, delimitar a mais adequada a cada situação apresentada. A partir disso, na trajetória profissional de uma das autoras do artigo, como enfermeira do trabalho, por um período de dez anos, em uma empresa no município de Santa Cruz do Sul - RS, foi possível observar e acompanhar, por diversas vezes, situações de acidentes de trabalho que originavam algum tipo de seqüela física importante. Como cuidadora, preocupava-Ihe a maneira como, a partir do evento acidentário, a trajetória desse acidentado era conduzida e a forma como atender profissionalmente esse trabalhador, a partir de diversas variáveis presentes nessa trajetória. A discriminação e o preconceito acabavam por envolver a situação, e o empregado era visto como um inútil, como um peso improdutivo que deveria ser sustentado.

Alguns autores vêm estudando as situações em que os indivíduos portadores de lesões decorrentes de sua atividade laboral são identificados como indivíduos incapazes para o trabalho e para a vida social ${ }^{(1-2)}$. Eles referem que esses trabalhadores são discriminados e prejudicados diretamente em suas relações profissionais, familiares e sociais, devido ao preconceito da sociedade em que convivem, em relação às seqüelas físicas do acidente e sofrem brutalmente com a existência destas e com as repercussões sociais, profissionais e afetivas advindas do acidente de trabalho.

Para operacionalizar a exposição dos fatos e o entendimento das ações, o presente texto baseou-se nas concepções apresentadas por Paterson e Zderad, em sua teoria que aborda a prática de enfermagem humanística, como um fator de compreensão para as diferentes perspectivas e atuações que podem contemplar o cotidiano da prática pessoal e profissional dos enfermeiros ${ }^{(3)}$. Assim, como enfermeiras cuidadoras e profissionais integrantes desse panorama, entendemos a importância de analisar as situações de atendimento ao acidentado. Nesse sentido, segundo a reflexão realizada neste texto, a conduta de ação elaborada pela teoria de Paterson e Zderad pode contemplar as necessidades e as escolhas a serem realizadas pelo enfermeiro e pela pessoa que sofreu um acidente de trabalho. $\mathrm{O}$ atendimento da enfermagem ao acidentado do trabalho deve ser uma resposta confortadora de uma pessoa para outra em um momento de necessidade, que visa ao desenvolvimento do bem-estar e do auxílio em aumentar a possibilidade de serem feitas escolhas responsáveis, pois é dessa forma que os seres humanos e, aqui, especificamente, os trabalhadores acidentados do trabalho, são capazes de tornarem-se, novamente, pessoas.

\section{UMA ABORDAGEM A RESPEITO DAS IMPLICAÇÕES PARA O TRABALHADOR ACIDENTADO E A UTILIZAÇÃO DA TEORIA DA PRÁTICA HUMANÍSTICA DE ENFERMAGEM}

O trabalho no Brasil, nos últimos quinze anos, levou pelo menos 60.000 pessoas à morte e originou 300.000 mutilados incapacitantes ${ }^{(4)}$. As estatísticas oficiais indicam a ocorrência anual de mais de um milhão de casos de acidentes de trabalho, com cerca de cinco mil mortes por esses mesmos acontecimentos. $\mathrm{O}$ autor refere que as estatísticas de acidentes de trabalho no Brasil têm confiabilidade discutível, existe subnotificação de dados, e prevalece o desinteresse dos envolvidos nos atendimentos administrativos e técnicos dos acidentados.

A situação de descaso que envolve essas informações inexatas relativas ao número de acidentes também é encontrada quando se analisa a situação desse trabalhador e sua adaptação à nova condição de vida, em seus diversos espaços sociais, determinada a partir do acidente $^{(1)}$. Muitas novas situações, antes nunca vivenciadas, apresentam-se após o acidente, como o preconceito da sociedade em se relacionar com pessoas com deficiências físicas e o seu comprometimento e das instituições com essa situação. A trajetória do acidentado, apesar da cobertura institucional, é marcada pela negação de sua condição de cidadão. A sociedade recusa-se a vêlo, é estigmatizado. A condição de acidentado não é somente a da força de trabalho sucateada, mas de cidadão sucateado $^{(2)}$. O novo status social e profissional adquirido interfere nas próprias relações de convívio com a sociedade e com o ambiente de trabalho.

Também a família, a partir do acidente, sofre repercussões muito intensas sobre as suas estratégias de sobrevivência. A adaptação da família e das pessoas que convivem com ele nessa nova situação, que impõe, abruptamente, novos estilos, novos comportamentos, 
novas vivências, não é um desafio fácil de ser vencido, levando, inclusive, às vezes, ao abandono da família.

$\mathrm{Na}$ teoria de Paterson e Zderad, é por meio das relações com os outros que o ser humano atinge o objetivo de ser interdependente, e isso, ao mesmo tempo, permite que ele, como indivíduo, também se realize ${ }^{(3)}$. Articulase, sob esse enfoque, a importância da presente teoria na compreensão da condição de acidentado do trabalho e na sistematização do atendimento de enfermagem, a partir dos valores e perspectivas que ambos (cliente e profissional) trazem a esse encontro. Assim, a compreensão da condição de acidentado e todas as implicações advindas dessa condição passam a nortear a atuação do profissional, pois a perspectiva de mundo do cliente é uma consideração vital para a enfermagem.

Por sua natureza humanista, a preocupação da enfermagem fenomenológica não é com o comportamento resultante, mas com o significado da experiência para o cliente. O resultado do processo de enfermagem, diferentemente do processo tradicional, caracteriza-se, por exemplo, pelo cliente que demonstra uma atividade indicadora de que o sofrimento está sendo ultrapassado. No caso do acidentado do trabalho, o retorno ao trabalho, em condições de reintegração e recolocação no espaço social, e o entendimento pela sociedade de suas necessidades são o maior indicativo disso, conforme as reflexões realizadas no presente estudo. Nessa situação, torna-se mais evidente que o resultado desse processo é, realmente, o objetivo do retorno e da reintegração do acidentado ao trabalho, à sociedade, à família, como um indicador do que a própria teoria nos diz, ao determinar isso, como seu principal objetivo.

\section{CONSIDERAÇÕES FINAIS}

Diante do panorama referido no presente trabalho, podemos considerar como é difícil a trajetória do acidentado nos diversos espaços em que transita, passando por todos os profissionais e instituições. As situações de descaso, desrespeito e de atendimento desumanizado são várias. Como profissionais da saúde, podemos auxiliar na modificação desse quadro, já que sabemos que a recuperação e o bem-estar de nossos clientes são influenciados diretamente pelo tipo de atendimento prestado pela enfermagem, assim como referem as teoristas Paterson e Zderad.

Entendemos que a teoria humanista pode auxiliar o enfermeiro na elaboração da trajetória e da conduta profissional a respeito dessa situação. Realmente, a visão fenomenológica situa-se como instrumento para compreensão da situação desse indivíduo como ser parcial ou totalmente incapacitado para exercer suas atividades laborais. Além disso, propicia o entendimento da complexidade da questão de ser tratado com preconceito e com discriminação, em todos os espaços sociais em que convive, atingindo e desestruturando, desse modo, 0 ser humano trabalhador, na sua integralidade.

\section{REFERÊNCIAS BIBLIOGRÁFICAS}

1. Krug SBF. A Condição de Acidentado Grave do Trabalho no município de Santa Cruz do Sul - RS: um estudo das trajetórias de vida após o evento. [dissertação]. Santa Cruz do Sul (RS): Universidade de Santa Cruz do Sul/UNISC; 2000. 2. Matsuo M. Acidentado do Trabalho: Reabilitação ou Exclusão? Brasília (DF): Ministério do Trabalho; 1998.

3. Praeger SG. Josephine E. Paterson e Loretta T. Zderad. In: George JB. Teorias de Enfermagem: os fundamentos à prática profissional. Porto Alegre (RS): Artes Médicas; 2000.

4. Coleta JAD. Acidentes do Trabalho. São Paulo (SP): Atlas; 1991. 